\title{
IMPLEMENTASI ASUHAN SAYANG IBU DI WILAYAH KERJA PUSKESMAS CANDIMULYO KABUPATEN MAGELANG PADA BULAN MEI TAHUN 2013
}

\author{
Iswari Paramita ${ }^{1}$, Mustika Pramestyani ${ }^{2}$, Mentari $^{3}$ \\ ${ }^{1}$ Dinas Kesehatan DIY, ${ }^{2,3}$ D3 Kebidanan STIKes Guna Bangsa Yogyakarta
}

\begin{abstract}
Background: Dear mother care is care with the principle of mutual respect for the culture, beliefs and desires of the mother. One basic principle is to include husbands and families during labor and childbirth. Attention and support to the mother during labor will gain a sense of security and a better output. Dear mother's care during childbirth include the care given to the mother, which began when I to stage IV. Dear mother care implementation or become a fundamental principle in the provision of care dear mother in the delivery process includes providing emotional support, provision of fluids and nutrition, flexibility for bladder and bowel, as well as the prevention of infection.
\end{abstract}

Objective: This study aims to determine the implementation dear mother care clinic working area Candimulyo.

Method: Type of approach used in this study is the evaluation of research method (Evaluation Study). Respondents in this study all private midwives working area clinic Candimulyo 20 the number of samples taken by the Non-Probability sampling techniques saturated.

Result: From the analysis of the implementation of the care of dear mother of this study showed that of the 20 respondents found the overall implementation of the care of maternal affection are quite as many as 13 respondents $(65 \%)$.

Conclusion: Implementation dear mother care clinic Candimulyo working area is quite.

Keywords: Dear mother care, childbirth

\section{PENDAHULUAN}

Asuhan sayang ibu merupakan asuhan persalinan dengan mengikutsertakan suami dan keluarga selama proses persalinan dan kelahiran bayi yang mampu mengurangi risiko terjadinya kematian ibu. Untuk menurunkan Angka Kematian Ibu terlihat beberapa program yang dilaksanakan oleh organisasi internasional misalnya program gerakan sayang ibu (safe motherhood program) yang dilaksanakan oleh World Health Organization (WHO) (2010).

Asuhan sayang ibu sebagai salah satu aspek dari 5 benang merah sangat membantu ibu agar merasa aman dan nyaman selama proses persalinan. Beberapa penelitian menunjukkan bahwa ibu tidak mau meminta pertolongan tenaga penolong persalinan terlatih untuk 
memberikan asuhan selama persalinan dan kelahiran bayi dengan alasan, bahwa tenaga penolong tersebut tidak benar-benar memperhatikan kebutuhan/ kebudayaan, tradisi, dan keinginan pribadi para ibu dalam persalinan dan kelahiran bayi.

Alasan lain yang juga berperan adalah bahwa sebagian besar fasilitas kesehatan memiliki peraturan dan prosedur kurang bersahabat dan menakutkan bagi para ibu. Peraturan dan prosedur tersebut termasuk; tidak memperkenankan ibu untuk berjalanjalan sebelum dilakukan proses persalinan, tidak mengizinkan anggota keluarga menemani ibu, membatasi ibu hanya pada posisi tertentu selama persalinan dan kelahiran bayi dan memisahkan ibu dari bayi segera setelah bayi dilahirkan (Waspodo, Djoko, dkk. 2007).

Banyak hasil penelitian menunjukkan bahwa jika para ibu diperhatikan dan diberi dukungan selama persalinan dan kelahiran bayi serta mengetahui dengan baik mengenai proses persalinan dan asuhan yang akan mereka terima, mereka akan mendapatkan rasa aman dan keluaran yang lebih baik (Enkin, et. all, 2000).

Berdasarkan hasil studi pendahuluan yang dilakukan di Dinas Kesehatan Kabupaten Magelang, dari data laporan pelayanan kesehatan tahun 2012 didapat 21 Bidan Praktek Swasta di Kecamatan Candimulyo, dari sebaran persalinan yang didapat dari laporan PWSKIA didapat 19 desa pada Kecamatan Candimulyo dan terdapat data jumlah persalinan pada tahun 2012 ditiap desa Kecamatan Candimulyo yaitu; Bateh 58 ibu bersalin, Tampir Wetan 42 ibu bersalin, Podosoko 25 ibu bersalin, Tegalsari 46 ibu bersalin, Kembaran 24 ibu bersalin, Tampir Kulon 51 ibu bersalin, Tempak 51 ibu bersalin, Sidomulyo 58 ibu bersalin, Mejing 73 ibu bersalin, Surojoyo 46 ibu bersalin, Candimulyo 34 ibu bersalin, Tempursari 12 ibu bersalin, Purworejo 34 ibu bersalin, Surodadi 107 ibu bersalin, Tembelang 27 ibu bersalin, Sonorejo 36 ibu bersalin, Giyanti 25 ibu bersalin, Kebonrejo 41 ibu bersalin, Trenten $87 \mathrm{ibu}$ bersalin dan diperoleh data absolute (ABS) $100 \%$ ditolong oleh tenaga kesehatan (Lap.Yankes, 2012).

Dari hasil wawancara dengan bidan yang bertugas dipuskesmas Candimulyo, bahwa Asuhan Sayang Ibu telah dilaksanakan namun belum pernah dilakukan penelitian untuk mengevaluasi Implementasi Asuhan Sayang Ibu Diwilayah Kerja Puskesmas Candimulyo. Berdasarkan dari uraian di atas, peneliti sangat tertarik untuk mengetahui lebih lanjut Implementasi Asuhan Sayang Ibu Di Wilayah Kerja Puskesmas Candimulyo.

\section{PEMBAHASAN}

1. Sebaran persalinan pada BPS diwilayah kerja Puskesmas Candimulyo pada bulan Januari April tahun 2013. 
Tabel 1 Rata-rata sebaran persalinan BPS wilayah kerja puskesmas Candimulyo pada bulan Januari April tahun 2013

\begin{tabular}{|c|l|l|c|}
\hline \multirow{2}{*}{ No. } & \multicolumn{2}{|c|}{$\begin{array}{c}\text { 20 BPS Diwilayah Kerja Puskesmas } \\
\text { Candimulyo }\end{array}$} & $\begin{array}{c}\text { Rata-rata } \\
\text { Sebaran } \\
\text { Persalinan } \\
\text { (perbulan) }\end{array}$ \\
\cline { 2 - 4 } & \multicolumn{2}{|c|}{ Desa } & \multicolumn{1}{|c|}{ Bidan } \\
\hline 1 & Bateh & Ni Wayan & 5 \\
\hline 2 & Tampir Wetan & Budi Tutiyani & 3 \\
\hline 3 & Podosuko & Indarini & 4 \\
\hline 4 & Tegalsari & Mamik & 4 \\
\hline 5 & Kembaran & Yuyun & 1 \\
\hline 6 & Tampir Kulon & Sri Haryanti & 4 \\
\hline 7 & Tempak & Titin Septina R & 6 \\
\hline 8 & Sidomulyo & Yani Purnamawati & 6 \\
\hline 9 & Mejing & Wiwik & 7 \\
\hline 10 & Surojoyo & Adi Sumirat & 3 \\
\hline 11 & Candimulyo & Eny Siswati & 2 \\
12 & & Hartiningsih & \\
\hline 13 & Tempursari & Citra & 2 \\
\hline 14 & Purworejo & Nurwahyuni & 5 \\
\hline 15 & Surodadi & Tri Widiyati & 7 \\
\hline 16 & Tembelang & Dwi Astuti & 6 \\
\hline 17 & Sonorejo & Sri Lestari & 2 \\
\hline 18 & Giyanti & Tri Asih & 3 \\
\hline 19 & Kebonrejo & Sri Maryanti & 3 \\
\hline 20 & Trenten & Sriyanti & 3 \\
\hline
\end{tabular}

Sumber : Data Primer Terolah, 2013.

Berdasarkan Tabel 1 dapat diketahui jumlah rata-rata sebaran persalinan dari bulan Januari - April tahun 2013 diperoleh jumlah terbesar berada didesa Mejing dan Surodadi sebesar 7 ibu bersalin. Hal ini sebanding dengan jumlah ibu hamil didesa Mejing dan Surodadi berdasarkan data PWS KIA tahun 2012.

2. Karakteristik ibu bersalin berdasarkan cara bayar persalinan diwilayah kerja Puskesmas Candimulyo pada bulan Mei tahun 2013. Untuk melihat karakteristik tersebut dilakukan penelitian di 20 BPS dan hanya diambil satu ibu bersalin untuk kemudian dilakukan observasi dimana diketahui bahwa berdasarkan cara bayar seperti berikut.

Tabel 2 Distribusi frekuensi karakteristik ibu bersalin berdasarkan cara bayar

\begin{tabular}{clcc}
\hline No & \multicolumn{1}{c}{ Kategori } & Frekuensi & $\begin{array}{l}\text { Presenta } \\
\text { se }(\%)\end{array}$ \\
\hline 1 & $\begin{array}{l}\text { Jaminan } \\
\text { Persalinan }\end{array}$ & 20 & 100 \\
\hline 2 & $\begin{array}{l}\text { Tidak Jaminan } \\
\text { Persalinan }\end{array}$ & 0 & 0 \\
\hline & Jumlah & $\mathbf{2 0}$ & $\mathbf{1 0 0 , 0}$ \\
\hline
\end{tabular}

Sumber : Data Primer Terolah, 2013.

Berdasarkan Tabel 2 dapat diketahui bahwa seluruh ibu bersalin yang menjadi responden penelitian ini menggunakan jaminan persalinan sebanyak 20 responden (100\%).

3. Proporsi implementasi asuhan sayang ibu saat persalinan diwilayah kerja Puskesmas Candimulyo pada bulan Mei tahun 2013. Untuk melihat proporsi tersebut bidan yang menjadi objek observasi penelitian sehingga dapat dikelompokan distribusi frekuensi sebagai berikut dengan data terolah diperoleh mean $=17,8$ dengan $\mathrm{SD}=0,5$.

Tabel 3 Distribusi frekuensi implementasi asuhan sayang ibu saat persalinan

\begin{tabular}{clcc}
\hline No & Kategori & Frekuensi & Presentase (\%) \\
\hline 1 & Baik & 17 & 85 \\
\hline 2 & Cukup & 2 & 10 \\
\hline 3 & Kurang & 1 & 5 \\
\hline Jumla & & $\mathbf{2 0}$ & $\mathbf{1 0 0 , 0}$
\end{tabular}

Sumber : Data Primer Terolah, 2013. 
Berdasarkan Tabel 3 menunjukan bahwa dari 20 responden implementasi asuhan sayang ibu saat persalinan paling banyak kategori baik yaitu sebesar $17 \mathrm{ibu}$ bersalin (85\%).

4. Proporsi implementasi asuhan sayang ibu pasca persalinan diwilayah kerja Puskesmas Candimulyo pada bulan Mei tahun 2013. Untuk melihat proporsi tersebut bidan yang menjadi objek observasi penelitian sehingga dapat dikelompokan distribusi frekuensi sebagai berikut dengan data terolah diperoleh mean $=4,2$ dengan

$\mathrm{SD}=0,41$.

Tabel 4 Distribusi frekuensi implementasi asuhan sayang ibu pasca persalinan

\begin{tabular}{clcc}
\hline No & Kategori & Frekuensi & $\begin{array}{c}\text { Presentase } \\
(\mathbf{\%})\end{array}$ \\
\hline $\mathbf{1}$ & Baik & 4 & 20 \\
\hline $\mathbf{2}$ & Cukup & 16 & 80 \\
\hline $\mathbf{3}$ & Kurang & 0 & 0 \\
\hline Jumlah & $\mathbf{2 0}$ & $\mathbf{1 0 0 , 0}$ \\
\hline
\end{tabular}

Sumber : Data Primer Terolah, 2013.

Berdasarkan Tabel 4 menunjukan bahwa dari 20 responden implementasi asuhan sayang ibu pasca persalinan paling banyak kategori cukup yaitu sebesar 16 ibu bersalin (80\%).

5. Proporsi implementasi asuhan sayang ibu diwilayah kerja Puskesmas Candimulyo pada bulan Mei tahun 2013. Untuk melihat proporsi tersebut bidan yang menjadi objek observasi penelitian sehingga dapat dikelompokan distribusi frekuensi sebagai berikut dengan data terolah diperoleh mean $=22$ dengan $\mathrm{SD}=0,7$.
Tabel 5 Distribusi frekuensi implementasi asuhan sayang ibu

\begin{tabular}{clcc}
\hline No & Kategori & $\begin{array}{c}\text { Frekuen } \\
\text { si }\end{array}$ & $\begin{array}{c}\text { Presentas } \\
\text { e (\%) }\end{array}$ \\
\hline $\mathbf{1}$ & Baik & 4 & 20 \\
\hline $\mathbf{2}$ & Cukup & 13 & 65 \\
\hline $\mathbf{3}$ & Kurang & 3 & 15 \\
\hline $\begin{array}{l}\text { Jumlah } \\
\mathbf{1 0 0 , 0}\end{array}$ & $\mathbf{2 0}$ & \\
\hline
\end{tabular}

Sumber : Data Primer Terolah, 2013.

Berdasarkan Tabel 4.7 menunjukan bahwa dari 20 responden implementasi asuhan sayang ibu paling banyak kategori cukup yaitu sebesar 13 responden $(65 \%)$.

Hasil analisis penelitian menunjukan bahwa rata-rata jumlah sebaran persalinan BPS wilayah kerja puskesmas Candimulyo tahun 2013 pada bulan Januari - April didapat jumlah rata-rata sebaran persalinan (perbulan) diperoleh jumlah terbesar berada didesa Mejing dan Surodadi sebesar 7 ibu bersalin. Hal ini sebanding dengan jumlah ibu hamil didesa Mejing dan Surodadi berdasarkan data PWS-KIA tahun 2012. Dilihat dari hasil penelitian Implementasi Asuhan Sayang Ibu yang mendapat kategori cukup dan sebaran persalinan hanya $7 \mathrm{ibu}$ bersalin atau hanya sedikit kenapa tidak dilakukan saja asuhan sayang ibu secara keseluruhan. Dengan demikian dapat disimpulkan bahwa sebaran persalinan tidak merata berdasarkan jumlah ibu hamil disetiap desa dan asuhan sayang ibu yang kurang diimplementasikan.

Dari hasil penelitian menunjukan bahwa dapat diketahui dari 20 pasien yang bersalin keseluruhannya menggunakan jampersal. Hal ini 
menunjukkan bahwa rata-rata ibu bersalin mendapat fasilitas dari pemerintah, dan dapat diketahui bahwa tidak ada perbedaan implementasi asuhan sayang ibu berdasarkan cara bayar. Berdasarkan Peraturan Menteri Kesehatan Republik Indonesia Nomor 2562/Menkes/ Per/ XII/ 2011 Tentang Petunjuk Teknis Jaminan Persalinan.

Dalam rangka menurunkan angka kematian ibu dan anak dan mempercepat pencapaian MDGs telah ditetapkan kebijakan bahwa setiap ibu yang melahirkan, biaya persalinannya ditanggung oleh Pemerintah melalui Program Jaminan Persalinan. Program Jaminan Persalian (Jampersal) adalah jaminan pembiayaan persalinan yang meliputi pemeriksaan kehamilan, pertolongan persalinan, pelayanan nifas termasuk pelayanan $\mathrm{KB}$ pasca persalinan dan pelayanan bayi baru lahir. Dengan demikian, dapat disimpulkan bahwa berdasarkan hasil penelitian Jampersal sudah berjalan dengan baik disetiap-tiap desa.

Dari hasil penelitian menunjukan bahwa dapat diketahui sebagian besar responden mengimplementasikan asuhan sayang ibu saat persalinan termasuk dalam kategori baik yaitu sebanyak 17 responden $(85 \%)$, dan pasca persalinan termasuk dalam kategori cukup yaitu sebanyak 16 responden $(80 \%)$. Asuhan sayang ibu merupakan asuhan persalinan dengan mengikutsertakan suami dan keluarga selama proses persalinan dan kelahiran bayi yang mampu mengurangi risiko terjadinya kematian ibu. Asuhan sayang ibu membantu ibu dan keluarganya untuk merasa aman dan nyaman selama proses persalinan.
Asuhan sayang ibu adalah asuhan dengan prinsip saling menghargai budaya, kepercayaan dan keinginan sang ibu (Depkes, 2004). Dengan demikian dapat disimpulkan penelitian pada implementasi asuhan sayang ibu saat persalinan dan pasca persalinan sudah sesuai dengan aturan kesehatan untuk selalu memberikan rasa aman dan nyaman pada proses persalinan.

Hasil dari penelitian tentang Implementasi Asuhan Sayang Ibu di Wilayah Kerja Puskesmas Candimulyo yang telah dilakukan didapat kategori cukup yaitu sebanyak 13 responden (65\%). Hal ini dipengaruhi karena kurangnya kerjasama yang baik antara bidan dan pasien, karena tingkat kecemasan wanita selama bersalin akan meningkat yang menyebabkan ibu bersalin kurang mendengarkan intruksi bidan.

Asuhan sayang ibu menjamin bahwa pasien dan keluarganya diberitahu tentang apa yang sedang terjadi dan apa yang bisa diharapkan. Sama seperti kala I, selama kala II bidan harus menjelaskan apa yang akan dilakukan serta alasannya sebelum melakukan tindakan (seperti sebelum melakukan pemeriksaan vagina, mengecek tekanan darah, DJJ, dsb), dan menjelaskan hasil pemeriksaan yang dilakukannya.

Bidan bertugas membantu pasien memahami apa yang sedang dan akan terjadi selama proses kelahiran, menghargai peran pasien, peran bidan, dokter atau pemberi asuhan lainnya dalam proses kelahiran tersebut (Marmi, 2012; Sulistyawati dan Nugraheny, 2010). Dengan demikian dapat disimpulkan pada penelitian ini 
belum sepenuhnya berkaitan dengan teori yang ada karena masih adanya batasan-batasan dalam implementasi sehingga tidak terpenuhinya Implementasi Asuhan Sayang Ibu.

\section{KESIMPULAN}

1. Berdasarkan rata-rata jumlah sebaran persalinan BPS wilayah kerja puskesmas Candimulyo dari bulan Januari - April tahun 2013 didapat jumlah rata-rata sebaran persalinan (perbulan) diperoleh jumlah terbesar berada didesa Mejing dan Surodadi sebesar 7 ibu bersalin. Hal ini sebanding dengan jumlah ibu hamil didesa Mejing dan Surodadi berdasarkan data PWS-KIA tahun 2012.

2. Dari hasil penelitian Implementasi Asuhan Sayang Ibu berdasarkan cara bayar, dari 20 pasien yang bersalin keseluruhannya menggunakan jampersal.

3. Implementasi asuhan sayang ibu saat persalinan didapatkan hasil termasuk dalam kategori baik yaitu sebanyak 17 responden $(85 \%)$.

4. Implementasi asuhan sayang ibu pasca persalinan didapatkan hasil termasuk dalam kategori cukup yaitu sebanyak 16 responden $(80 \%)$.

5. Hasil dari penelitian tentang Implementasi Asuhan Sayang Ibu di Wilayah Kerja Puskesmas Candimulyo yang telah dilakukan didapat kategori cukup yaitu sebanyak 13 responden (65\%). Pada penelitian ini belum sepenuhnya berkaitan dengan teori yang ada karena masih adanya batasan-batasan dalam implementasi sehingga tidak terpenuhinya Implementasi Asuhan Sayang Ibu.

\section{SARAN}

1. Bagi Bidan Praktek Swasta Diwilayah Kerja Puskesmas Candimulyo Untuk selalu melakukan asuhan sayang ibu saat persalinan dan pasca persalinan untuk mengeratkan hubungan emosional antara ibu bersalin dengan bidan dan memberikan rasa nyaman.

2. Bagi Ibu Bersalin

Setiap ibu bersalin wajib secara aktif menanyakan hak dan kewajibannya agar mendapatkan kenyamanan dan keamanan dari tenaga kesehatan.

3. Bagi Peneliti Lain

Meneliti disalah satu BPS dalam jangka tertentu dan melakukan observasi terlibat agar bidan yang menjadi sasaran observasi tidak merasa terawasi.

\section{DAFTAR PUSTAKA}

Arikunto, S.2010. Prosedur Penelitian Suatu Pendekatan Praktek. Jakarta : Rineka Cipta.

Arikunto, S.2006. Prosedur Penelitian Suatu Pendekatan Praktek. Jakarta : Rineka Cipta.

Bobak, L.2005. Buku Ajar Keperawatan Maternitas, edisi 4. Alih Bahasa : Maria A. Wijayarini. Jakarta : EGC

Depkes RI.2007. Rencana Strategi Nasional Making Pregnancy Safer (MPS) di Indonesia Tahun 2001-2010. Jakarta : Dinas Kesehatan Republik Indonesia. 
Dinkes Magelang.2012. Profil Kesehatan. Magelang : Dinas Kesehatan Magelang.

Marmi.2012. Intranatal Care, Asuhan Kebidanan Pada Persalinan. Yogyakarta : Pustaka Pelajar.

Hidayat, A., Mufdillah.2008. Catatan Kuliah Konsep Kebidanan. Yogyakarta : Mitra Cendekia Press

Notoatmodjo, S.2010. Metodelogi Penelitian Kesehatan. Jakarta : PT. Rikena Cipta.

Prawirohardjo, S.2006. Obstetri dan Ginekologi. Jakarta : Widya Medika.

Prawirohardjo, S.2007. Obstetri dan Ginekologi. Jakarta : Widya Medika.
Prawirohardjo, S., H. Carey, C.S.2008. Obstetri dan Ginekologi. Jakarta : Widya Medika.

Sulistyawati, A., Nugraheny, E.2010. Asuhan Kebidanan Pada Ibu Bersalin. Jakarta : Salemba Medika.

Sugiyono.2012. Statistika Untuk Penelitian. Bandung : ALFABETA.

http ://www.pdf.com/ Analisis Penerapan Standar Asuhan Persalinan Normal (APN) Oleh Bidan Di Rumah Sakit Umum Daerah Kabupaten Sorong Papua Barat Tahun 2008 ( STUDI KUALITATIF ).html 